\title{
Trainspotting: uma perspectiva psicanalítica da toxicomania na contemporaneidade
}

\author{
Flávia Angelo Verceze ${ }^{1}$ \\ Sílvia Nogueira Cordeiro ${ }^{2}$
}

\begin{abstract}
O uso de substâncias consideradas tóxicas consiste em uma prática milenar presente em diferentes povos e culturas. Todavia, em cada civilização ou época, a droga apresenta uma finalidade diferente. Na contemporaneidade o uso de drogas está relacionado ao modo de vida e aos ideais vigentes no contexto social, caracterizado fundamentalmente por uma cultura do narcisismo e do espetáculo. Partindo dessa concepção de droga presente na atualidade e do pressuposto de que a subjetividade humana e as patologias são construídas a partir de articulações das relações culturais com a história individual do sujeito, o presente artigo tem como objetivo discutir o fenômeno da toxicomania na contemporaneidade através de vinhetas do filme Trainspotting. Para fundamentar essa discussão, utilizará o referencial teórico psicanalítico.
\end{abstract}

Descritores: Toxicomania; Psicanálise; Contemporaneidade; Narcisismo.

\footnotetext{
${ }^{1}$ Psicóloga, Aluna do curso de "Residência Multiprofissional em Saúde da mulher", Universidade Estadual Londrina, Londrina, PR, Brasil.

${ }^{2} \mathrm{PhD}$, Professor Adjunto, Universidade Estadual de Londrina, Centro de Ciências Biológicas, Londrina, PR, Brasil.
}

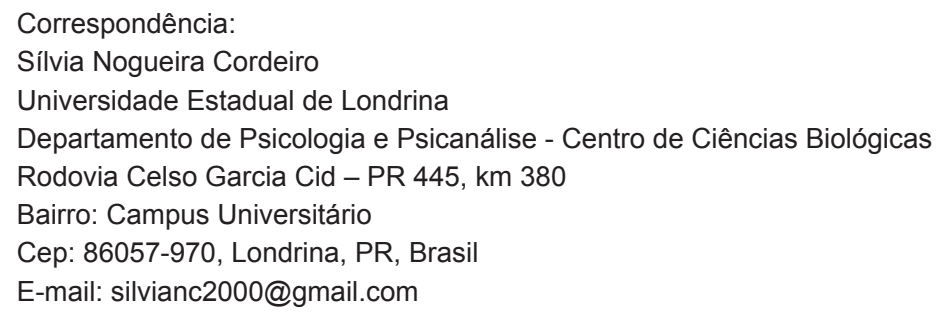




\section{Trainspotting: A psychoanalytic perspective of drug addiction in contemporary society}

The use of substances considered toxic is an ancient practice found in different peoples and cultures. However, in each civilization or time, drug has a different purpose. In contemporary society, drug use is related to the way of life and the prevailing ideals in the social context, fundamentally characterized by the culture of narcissism and spectacle. From this drug conception in modernity and the assumption that human subjectivity and pathologies are built from articulations of cultural relationships with the subject's individual history, this article aims to discuss the drug addiction phenomenon in contemporary society through vignettes of the film Trainspotting. To support this argument, the psychoanalytic theory approach is used.

Descriptors: Drug Addiction; Psychoanalysis; Contemporaneity; Narcisism.

\section{Trainspotting: Una perspectiva psicanalítica de la toxicomanía en la contemporaneidad}

El uso de substancias consideradas tóxicas consiste en una práctica milenaria presente en diferentes pueblos y culturas. Todavía, en cada civilización o época, la droga presenta una finalidad diferente. En la contemporaneidad el uso de drogas está relacionado al modo de vida y a los ideales vigentes en el contexto social, caracterizado fundamentalmente por una cultura del narcisismo y del espectáculo. Partiendo de esa concepción de droga presente en la actualidad y del presupuesto de que la subjetividad humana y las patologías son construidas desde articulaciones de las relaciones culturales con la historia individual del sujeto, el presente artículo tiene como objetivo discutir el fenómeno de la toxicomanía en la contemporaneidad a través de viñetas del film Trainspotting. Para fundamentar esa discusión, utilizará el referencial teorético psicanalítico.

Descriptores: Adicción a las Drogas; Psicoanálisis; Contemporáneo; Narcisismo.

Introdução

O uso de drogas não é uma prática recente. Sabe-se que o uso de substâncias consideradas tóxicas consiste em uma prática milenar presente em diferentes povos e culturas. Todavia, em cada civilização ou época, a droga apresenta uma finalidade diferente dentro daquele grupo.

Nas sociedades primitivas, o uso dessas substâncias estava relacionado a certos rituais de caráter mítico. Outrora, nas sociedades antigas, destinavam-se a vários fins, como, por exemplo, parte integrante de rituais religiosos, finalidade terapêutica, forma de lazer, entre outros ${ }^{(1)}$. Na Idade Média, com o advento da ética cristã, as substâncias tóxicas passaram a ser vistas como imorais e pecaminosas, e o seu uso proibido(1).

Na modernidade, com a implantação do modo de produção capitalista e o surgimento das ciências, o uso de substâncias tóxicas deixa de ser condenável e seu valor medicinal é legitimado(1). A partir do século XIX, com a Revolução Industrial, o uso de drogas ganha uma nova forma de expressão, que está relacionada ao modo de vida e aos ideais vigentes neste novo 
contexto social. As drogas, tanto lícitas quanto ilícitas, assumem a condição de objetos de consumo, que, como outros objetos, possuem a função de obtenção do prazer a qualquer custo(1).

Essa associação entre o uso de drogas e consumismo ainda pode ser observada nos dias de hoje. A sociedade contemporânea ou pósmoderna apresenta como imperativo o consumo e a necessidade de se viver sem nenhuma dor. Isso tem causado grande impacto nas patologias atuais, entre elas, a toxicomania. Partindo dessa concepção da droga na modernidade, muitos autores caracterizam a sociedade atual fundamentalmente por uma cultura do narcisismo e do espetáculo, na qual o individualismo e o autocentramento do sujeito adquirem proporções enormes. Ocorre um desaparecimento gradual do outro, que leva o prazer do sujeito pós-moderno a ficar reduzido ao investimento narcísico(2).

Assim, diante deste novo contexto, o que se tem verificado na clínica psicanalítica são sintomatologias que não seguem a lógica do conflito, do recalque e da representação, mas patologias com a presença de quadros narcísicos, ou seja, da ordem da ação. Nelas não há a presença de uma construção representativa; a pulsão é descarregada no ato ou no corpo e, por isso, são chamadas por muitos autores de psicopatologias do ato $^{(3)}$. São consideradas como pertencentes a esse grupo de doenças do narcisismo, ou do ato, a depressão, a anorexia, a obesidade, a bulimia, o transtorno do pânico e a adiç̧ão ou toxicomania. Conservando suas particularidades, eles apresentam como elemento comum manifestações que privilegiam o corpo e a ação e, como sua característica principal, a carência narcísica constitutiva ${ }^{(3-4)}$.

Assim, partindo da concepção de droga presente na contemporaneidade e do pressuposto de que a subjetividade humana e as patologias são construídas a partir de articulações das relações culturais com a história individual do sujeito, o presente artigo tem como objetivo discutir o fenômeno da toxicomania na contemporaneidade através de vinhetas do filme Trainspotting.

É importante salientar que não defendemos a concepção de que essas patologias surgiram com a contemporaneidade. $\mathrm{O}$ que entendemos é que elas existiam anteriormente, mas que a cultura atual tem favorecido tanto o aumento dessas patologias como o surgimento de novas sintomatologias, nas quais a elaboração psíquica cede lugar à ação, acometendo sujeitos que apresentam uma considerável fragilidade narcísica.

Também é relevante dizer que nem todo consumo de drogas pode ser entendido como uma patologia do narcisismo. O funcionamento psíquico dos toxicômanos difere do usuário recreativo da droga, considerando-se que esse indivíduo utiliza as substâncias em seus momentos de angústia ou de diversão, consumindo-as regular ou irregularmente, mas elas não se transformam no motivo maior de sua existência(5).

A escolha do filme Trainspotting, de 1996, adaptação do romance homônimo de Irvine Welsh para o cinema, deve-se ao fato de apresentar grande relação com os conceitos da psicanálise utilizados no presente artigo para o entendimento do fenômeno da toxicomania.

\section{A droga em Freud e em Lacan}

Freud não se dedicou especificamente à temática das drogas, embora o tema do uso e abuso de substâncias tóxicas apareça em alguns períodos ao longo da sua obra. Os principais sentidos atribuídos às toxicomanias por Freud estavam presentes no período pré-psicanalítico, anterior a 1900. Analisando esses textos da teoria freudiana, é possível perceber que o uso de drogas é associado às dependências em geral.

Em seu texto Carta a Fliess de 11 de janeiro de 1897, o autor apresenta uma preocupação com a origem do componente tóxico das paixões em geral, referindo-se à dipsomania (Impulso de ingerir bebidas alcoólicas) como uma substituição do impulso sexual. Diante disso, é possível perceber que esse texto nos fala de uma pulsão sexual originária que estaria nas bases de outras pulsões tóxicas( ${ }^{(6)}$.

$\mathrm{Na}$ Carta a Fliess de 22 de dezembro de 1897, Freud fará sua contribuição fundamental para responder à questão sobre a origem das toxicomanias, com destaque à masturbação, apresentando-a como protótipo das toxicomanias, isto é, destacará a masturbação como sendo a primeira toxicomania: "Comecei a compreender que a masturbação é o grande hábito, o 'vício primário', e que somente como sucedâneo e substituto dela que outros vícios --- álcool, morfina, tabaco, etc. --- adquirem existência"(7). Desta maneira, as diversas compulsões ou adicções são aproximadas à masturbação, que é considerada um comportamento autoerótico, ou seja, um comportamento sexual em que o sujeito recorre unicamente ao seu próprio corpo ${ }^{(7)}$. Posteriormente, outro texto de Freud, que pode ser usado para entender o significado da droga para o sujeito, é o Mal-estar na Civilização. Embora o autor não tenha se referido a esta temática especificamente nesse texto, ele apresenta a ideia de medidas paliativas, ou 
seja, maneiras que o sujeito encontra para suportar o mal-estar causado pela civilização, que em troca da segurança, impõe ao sujeito sacrifícios à sexualidade e agressividade inerente ao ser humano(8):"A vida, tal como a encontramos, é árdua demais para nós; proporciona-nos muitos sofrimentos, decepções e tarefas impossíveis. A fim de suportá-la, não podemos dispensar as medidas paliativas. [...] Existem talvez três medidas desse tipo: derivados poderosos, que nos fazem extrair luz de nossa desgraça; satisfações substitutivas, que a diminuem; e as substâncias tóxicas, que nos tornam insensíveis a ela"(8).

Neste sentido, é possível perceber que Freud considera a intoxicação a medida paliativa mais grosseira e a mais eficaz em proporcionar uma redução do mal-estar diante da exigência de renúncia de satisfação pulsional, pois a droga, ao influir sobre o organismo e alterar a química deste, promove efeitos no corpo, funcionando como um amortecedor de preocupações, o que leva o indivíduo a afastar-se da pressão da realidade. Deste modo, a função da droga é vista como um modo substitutivo de satisfação da pulsão, uma solução encontrada pelos sujeitos para lidar com o sofrimento próprio da cultura ${ }^{(9)}$.

Quando Freud se refere às drogas como medidas paliativas, ele passa a ideia de que o uso de drogas seria um esforço de economia psíquica na busca do caminho mais curto para o prazer. O efeito das drogas sobre o psiquismo seria provocar uma regressão da libido para etapas anteriores do desenvolvimento, como o narcisismo primário(10). Dessa maneira, é possível perceber que, para compreender o fenômeno da toxicomania, o narcisismo primário descrito pelo autor apresenta-se como conceito chave.

O que está em risco na toxicomania não é apenas a experiência de prazer que a substância tóxica provoca no organismo, mas uma experiência de prazer correlata à interferência provocada pela droga na posição do sujeito em relação ao objeto ou realidade, um tipo de prazer que pode ser qualificado como narcisista ${ }^{(10)}$. Essa busca de voltar a um prazer ilimitado, característico do narcisismo primário, pode ser compreendida como a escolha de um caminho sempre mais curto pelos atalhos que evitam a realidade e o desprazer, mas que conduz também a uma tendência de desmantelamento da própria vida psíquica e pulsional(10).

Assim, pode-se dizer que, no início da psicanálise, Freud revela acreditar na dominância do princípio do prazer, ou seja, que este regularia todos os eventos mentais em busca de uma redução de tensão; evitar o desprazer ou produção de prazer. Todavia, é preciso dizer que o autor, no decorrer de sua obra, realiza mudanças em sua teorização, evidenciadas em seu texto Além do princípio do prazer.

Sob a influência dos instintos de autopreservação do ego, o princípio do prazer é substituído pelo princípio de realidade. Este não abandona a intenção de obter prazer, mas exige e efetua o adiamento da satisfação, o abandono de uma série de possibilidades de obtêla e a tolerância temporária ao desprazer ${ }^{(11)}$. Os instintos sexuais, com frequência, conseguem vencer o princípio de realidade e chegam por caminhos indiretos a uma satisfação direta ou substitutiva. Esse acontecimento, entretanto, que em outros casos seria uma oportunidade de prazer, é sentido pelo ego como desprazer(11).

Desta maneira, é possível perceber que, neste texto, Freud contesta a dominância do princípio do prazer, que o leva a abandonar a dicotomia entre instintos de ego e instintos sexuais, substituindo-a pela dicotomia entre pulsão de vida e pulsão de morte. Esta última estaria relacionada a um caráter retrógrado, correspondente a uma compulsão à repetição, sempre procurando restaurar o estado inanimado, ou seja, uma posição em que não existia tensão e, portanto, desprazer: "Se procurar restaurar um estado anterior de coisas constitui característica tão universal dos instintos, não precisamos supreendernos com que tantos processos se realizarem na vida mental independente do princípio do prazer. Essa característica seria compartilhada por todos os instintos componentes e, em seu caso, visariam a retornar mais uma vez a uma fase específica do desenvolvimento"(11).

Esta fase específica à qual o autor se refere está relacionada aos processos primários, como o narcisismo primário, em que o princípio do prazer operava. Assim, é possível perceber que Freud chega ao final de sua conceituação, dizendo que o princípio do prazer parece na realidade servir aos instintos de morte.

Seguindo este raciocínio apresentado na teorização de Freud, Lacan realiza sua contribuição a respeito da temática. Assim, ao traçarmos um panorama do percurso de Lacan referente as drogas, vemos que sua primeira alusão ao tema ocorreu em 1938 em Os complexos familiares na formação do indivíduo, em que relacionou a toxicomania ao traumatismo psíquico do desmame. Onde considerou a toxicomania um retorno, mesmo que parcial, ao período em que o sujeito estava fundido à imago paterna , isto é, da representação inconsciente do pai e da sua função(12).

Posteriormente, Lacan, em Formulações sobre a causalidade psíquica, defende a ideia de que o recurso à droga é uma busca de unidade através 
de um complemento imaginário. Neste, ele aponta a intoxicação como um exemplo que nos permite entender que no início não há um sujeito(13). Diante disso, percebe-se que, para compreendermos o fenômeno da toxicomania na teoria lacaniana, é inevitável falar sobre a questão do sujeito (Sujeito do inconsciente) e consequentemente do Édipo, segundo esta, a constituição da subjetividade, isto é, a dimensão simbólica do sujeito, se dá através da passagem pelo Édipo.

Assim, ao passo que Freud tentava definir psicologicamente o complexo de Édipo, Lacan vai além e formula uma teoria do Édipo como estrutura que determina os fenômenos psicológicos do sujeito. Isto é, Lacan pensa o Édipo como uma "estrutura estruturante", externa ao sujeito e que o determina dessa maneira ${ }^{(14)}$. O Édipo não é mais visto como complexo, mas como lei. Lacan elabora uma reformulação da teoria do narcisismo e passa a interpretar o complexo de Édipo como metáfora paterna, mecanismo que é responsável pela inserção do sujeito na ordem simbólica(14-15).

Este Édipo, como metáfora paterna, é pensado em torno da função paterna, conceito que articula com os conceitos de falo e complexo de castração, que é uma representação simbólica da ameaça de desaparecimento na medida em que esta não concerne ao pênis, objeto real, mas ao falo, objeto imaginário(15) . Assim, ao acender ao simbólico, o sujeito se divide abrindo caminho para algo do desejo, da fantasia e do inconsciente. No entanto, isso ocasiona uma perda do gozo ilimitado, característico de um período em que o indivíduo ainda indiferenciado estava fundido à imago materna. Isso leva o indivíduo a viver em uma relação contínua com uma falta de satisfação que possibilita a instituição do desejo e somente a partir dele é que o sujeito surge ${ }^{(1)}$.

Entretanto, tal desejo permanece sempre insatisfeito, levando o sujeito a sentir uma imensa angústia, que faz com que esteja sempre em busca de algo que possa criar a ilusão de completude. Nesse ponto de vista, o recurso da intoxicação pode estar servindo como uma solução para completar imaginariamente essa falta, fazendo com que a única falta reivindicada pelo toxicômano seja a droga, que permite que ele não se depare com o inconveniente da castração. "As relações que cada sujeito estabelecerá com as drogas são sempre meios singulares de lidar com o desprazer, com o mal-estar, com a castração, e em última instância, com a divisão subjetiva"(1).

Assim, a adicção às drogas se configura como uma resposta ao sofrimento que demandaria uma simbolização, mas o sujeito responde através da ação, fazendo uma eleição do gozo que suprime a falta e só aceita o gozo que é obtido no próprio corpo. Deste modo, Lacan parte de sua descoberta analítica sobre a divisão do sujeito para articular o recurso às substâncias tóxicas com seu conceito de gozo(1).

O termo gozo na obra de Lacan aparece desde 1938 até o fim. No começo, ele se confunde com o termo prazer. Posteriormente, se diferencia e tornase um conceito central na tópica lacaniana ${ }^{(16)}$. Lacan parte da leitura do texto 0 mal-estar na civilização de Freud para criar a oposição entre gozo e prazer. Para ele o prazer seria evitar a dor e justamente neste ponto, em segundo plano, apareceria o gozo. Isto é, ele entende que o princípio do prazer e o princípio da realidade servem ao princípio do não desprazer. No entanto, existe algo que força essa barreira e é isso em que consiste o gozo(16). Assim, gozo e o prazer não pertencem mais ao mesmo registro. Portanto, depois de Freud, Lacan apresenta sua ideia de como se opera o aparelhamento do gozo pela linguagem, dizendo que o gozo pode ser delineado pelo discurso, que produz diferentes modalidades de emergência deste $^{(17)}$.

Uma dessas modalidades é o gozo fálico, que se sustenta nas relações de poder, isto é, nas relações sociais. Ele tem no falo o centro de sua organização e uma referência permanente. É um gozo sexual, que resulta da tradução do gozo corporal pelo significante, sendo, portanto, o gozo da fala, fora do corpo. É limitado e submetido à ameaça de castração(18).

Porém, este gozo fálico é recusado pelo toxicômano, uma vez que ele não se submete ao gozo universalizado da civilização. O casamento com a droga viria a substituir o casamento com o atributo fálico, criando uma nova forma de gozo, que rompe com o tradicional, sexual ou fálico, subordinando-o a um gozo do Outro, fora do simbólico, pois é da ordem do real e não gira em torno do falo(1). Assim, o recurso da intoxicação consiste em uma maneira encontrada pelo sujeito de não se deparar com a castração. Isto é, o sujeito passa a se suprimir como sujeito do desejo(1).

Em sua conferência O lugar da psicanálise na medicina, Lacan vai compreender os tóxicos como produtos da ciência. Aqui, ele apresenta sua ideia de que a atividade científica é uma forma de discurso, ou seja, uma forma de saber que assume poderes no plano do laço social. Nesta perspectiva, o recurso do toxicômano às drogas é apenas mais um efeito, entre muitos, que a ciência produz no mundo(19).

Por detrás dessa concepção adotada pelo autor está o conceito por ele descrito como gadgets, termo 
inglês que caracteriza invenções forjadas pela ciência, sem valor de uso, mas com função de oferecer aos sujeitos meios de uma fictícia recuperação da satisfação pulsional. Desta maneira, o recurso à droga estaria objetivando à recuperação desta satisfação e exercendo efeitos sobre o corpo dos indivíduos, o que tornaria possível uma relação de gozo(1).

Essas fabricações da ciência, por oferecerem ao sujeito os meios de uma recuperação da satisfação pulsional, fazem com que este se ligue a eles, até mesmo agarrando e fixando-se neles. E é nisso que consiste o efeito real da ciência sobre o corpo. No caso das drogas, elas passam a responder à questão do gozo do corpo, ou seja, a ciência fornece operadores químicos capazes de se constituírem em reguladores da própria economia libidinal, cuja única finalidade é extrair satisfação(20). Ao se referir a essa característica da droga, Lacan refere-se à ideia de que a pulsão pode ser satisfeita com um objeto nocivo ao indivíduo e, assim, a adesão profunda do toxicômano à droga não pode se explicada senão sob o ponto de vista do gozo, o que leva a concebê-la como um modo particular de satisfação(20).

Desta maneira, é possível perceber que, embora Freud e Lacan não tenham se dedicado muito sobre a temática das drogas, muitos autores atuais utilizamse de conceitos apresentados por eles para entender o fenômeno da toxicomania na pós-modernidade.

\section{Trainspotting: a toxicomania como sintoma da} pós-modernidade

O filme Trainspotting, drama dirigido por Danny Boyle de 1996 traz, por meio da odisseia vivida pela personagem Mark Renton em sua busca por largar a heroína, uma franca reflexão sobre a sociedade pós-moderna e os valores aos quais ela se mantém ligada. Assim, é possível fazer uma aproximação do filme com o estudo psicanalítico de alguns autores a respeito da toxicomania, que a entendem como um sintoma decorrente das transformações da pósmodernidade e seus aspectos socioculturais vigentes, como o ideal de consumo.

O consumismo moderno segue a lógica do prazer a qualquer preço que é disseminado pelos meios de comunicação na contemporaneidade. Nesta lógica, o que atrai o consumidor não é a real utilidade do produto, mas, a promessa de felicidade associada a este. Através da aquisição desse produto o sujeito estaria livre da falta, do vazio de sua existência. Assim, segundo esses autores, as drogas seriam mais um objeto de consumo, capazes de proporcionar a obtenção rápida e fácil de prazer, de forma comparável aos gadgets ${ }^{(1-2)}$.

Esta associação das drogas com outros produtos de consumo é evidenciada logo no começo do filme, na cena em que o personagens Renton e Spud estão correndo da polícia, à medida que o narrador (Renton) vai listando vários produtos e ideais consumistas pregados pela sociedade como formas de obtenção de prazer e, também, como um meio de se enquadrar na lógica social: "Escolha viver, escolha um emprego, escolha uma carreira, escolha uma família, escolha uma televisão enorme, escolha lavadoras, carros, cd players, abridores de lata elétricos, escolha saúde, colesterol baixo e plano dentário. Escolha uma hipoteca a juros fixos, escolha sua primeira casa, escolha seus amigos, escolha roupas esportes e malas combinando, escolha um terno em uma variedade de tecidos. [...] Mas por que eu iria querer isso? Escolhi não viver, escolhi outra coisa. E os motivos? Não há motivos. Quem precisa de motivos quando tem heroína?"

Esta primeira fala do personagem vai muito além de demonstrar a associação da droga com o ideal consumista. Ela pode exemplificar a função que a droga adquire na economia pulsional do sujeito toxicômano. No fenômeno da toxicomania a parceria entre o sujeito e a droga é caracterizada pelo assujeitamento do primeiro pelo segundo, fazendo com que o sujeito perca a via de acesso a seu desejo. A substância assume, assim, o caráter de um objeto insubstituível, de valor absoluto, que tem a capacidade de neutralizar o efeito da divisão subjetiva(1).

Essa capacidade da droga pode ser evidenciada na fala de Renton, quando está explicando sua relação com a heroína no início do filme: "As pessoas pensam que é tudo sofrimento, desespero, morte, o que não se pode ignorar. Mas elas se esquecem de que há prazer nisto. Caso contrário, não faríamos isso". Outro ponto, que pode ser observado através dessa fala é a ideia trazida por Freud, em que a busca de prazer obtida pelo uso de drogas representaria uma forma de satisfação substitutiva, ou seja, uma medida paliativa frente ao mal-estar advindo da sociedade. Assim, o fenômeno do vício surge como uma resposta possível e compatível com a sociedade atual, fundamentalmente narcísica, que prima pela obtenção do prazer, priorizando a autossuficiência em detrimento da dimensão social e política(1).

No caso do toxicômano, há um rompimento com a cultura; as drogas vêm para obturar a angústia que surgiria do encontro do sujeito com o desejo do Outro(21). A fuga dessa angústia através do uso 
da droga pode ser evidenciada no filme, quando os personagens decidem parar de usar as drogas e começam a se deparar com algumas situações no cotidiano de suas vidas que causam mal-estar e sofrimento, o que os leva a voltar a usar a droga. Desta maneira, pode-se dizer que as drogas apresentam um caráter "apaziguador", ou seja, têm um suposto efeito de completude.

Assim, é possível perceber que o toxicômano é aquele que recusa a castração, permanecendo no campo do gozo (Não fálico). Ele encontra um modo de substituição da sexualidade, conjugando amor e gozo em só produto, a droga. O que fica bem evidente no fenômeno da toxicomania é a questão do esgarçamento dos vínculos sociais do sujeito, fazendo com que suas relações se constituam de forma extremamente precária e frágil(21). Essa questão na toxicomania aparece de forma clara no filme, pois quase todos os personagens adictos têm seu círculo social reduzido a seus familiares, ao fornecedor da droga e aos companheiros de uso.

A toxicomania é como uma técnica de manipulação do próprio corpo com o objetivo de extrair-lhe gozo. E trata-se de um gozo particular, regulado pelo Outro, sendo, portanto, não fálico. Desta maneira ela objetiva recuperar parte do gozo primitivamente perdida a partir da inscrição da função fálica(1). Isto posto, o toxicômano se recusa a entrar no gozo fálico, optando por um gozo mortífero. Esta relação do toxicômano com a droga é percebida nesta fala do personagem Renton: "[...] relações humanas, todas as coisas que não importam pra quem tem um vício sincero".

O gozo do toxicômano se dá inseparavelmente do próprio corpo. Não passa pelo corpo do Outro, o que o torna cínico, considerando-se o cínico aquele que goza à revelia do corpo do Outro. Isto é, o toxicômano é um sujeito que recusa o gozo fálico, que é aquele que se sustenta nas relações humanas. Ele é aquele que se recusa a participar dessas relações, colocando-se às margens dela(18). Ainda segundo o mesmo autor, o toxicômano, ao recusar o gozo fálico, teria um gozo mortífero, o que valeria dizer que o significante mestre desse indivíduo é a morte. Assim, a imagem deste gozo vem destituída do simbólico, isto é, o sujeito toxicômano rompe com as relações sociais e "casa" com a droga. Casamento que representa o enlaçamento com o absoluto, com ele próprio, e o Outro deixa de existir para ele ${ }^{(18)}$.

Todas essas questões colocam a toxicomania no rol das patologias do ato, longe de ser um sintoma. "Quando a abordagem se realiza fora da castração, sem fantasia, direto no real, temos o gozo mortífero, pois a dimensão sexual foi foracluída. É quando o real recebe uma interpretação não sexual, como a morte, que está fora de significação. [...] Com o recrudescimento das toxicomanias, estamos assistindo ao triunfo do gozo não metaforizado, o gozo que não é regido pelo significante, e que produz o sujeito ssujeitado, dependente e escravizado a esse objeto de gozo"(18). Essa subordinação é muito visível no filme, que mostra como os personagens apenas conseguem viver em função do uso da droga, até mesmo as fases de abstinência. Assim, o sujeito, através do uso da droga, passa a rejeitar o Outro e a crer unicamente em seu próprio gozo, rompendo geralmente com as relações sociais para ficar com o tóxico.

Há outras duas cenas do filme que podem exemplificar essa situação de maneira muito clara. A primeira se refere à morte da criança no berço por falta de cuidados de sua mãe, que é usuária de heroína. Esta cena extremante forte deixa claro como, na toxicomania, há um completo apagamento do outro e das relações sociais e o sujeito vive apenas para usar a droga. A segunda quando o personagem Renton diz supostos amigos, ao se referir aos seus amigos com quem convive no uso das drogas, o que demonstra a fragilidade dos vínculos sociais.

Outro aspecto do filme que pode ser relacionado à conceituação lacaniana a respeito das drogas é referente à questão dos gadgets, ou seja, invenções forjadas pela ciência com função de oferecer aos sujeitos meios de uma fictícia recuperação da satisfação pulsional. No filme, a droga em evidência é a heroína, que constitui uma droga semissintética. Portanto, é uma droga inventada pela ciência, que pode ser consumida como forma de obter, supostamente, uma satisfação pulsional.

Em função disso, pode-se dizer que a toxicomania possui também uma causa social, uma vez que o uso de drogas estaria associado ao ideal da sociedade de consumo. Esse ideal torna abundante a oferta de prazer fácil, rápido e disponível. Deste modo, promove uma subjetividade dos indivíduos em que os gadgets estariam no lugar de objetos causa de desejo, servindo para tamponar a falta do sujeito.

Assim, na modernidade, os objetos a serem perseguidos são frágeis e mudam com frequência. A satisfação não pode ser depositada no futuro, tem que se consumir instantaneamente. Os indivíduos, procuram uma satisfação imediata justificada pela lógica 'goze agora a qualquer preço'. Este fenômeno é visível nos usuários de droga, que optam por estas a fim de uma satisfação rápida e fácil(22). Esta relação 
da toxicomania com o ideal de consumo da sociedade atual e sua associação com as produções do discurso científico é percebida durante o filme, que mostra como a droga é utilizada pelos personagens como forma substitutiva de obter prazer, deixando de lado quase todas as outras áreas de sua vida, como a profissional, familiar e amorosa.

Dessa maneira, observamos através dos pontos discutidos no presente artigo, que segundo uma visão freudiana e lacaniana do fenômeno da toxicomania, ela não é concebida como um sintoma no estrito sentido freudiano, por não se constituir do mesmo modo que as clássicas formações do inconsciente, que implicam um retorno do recalcado e envolvem a vertente simbólica.

Com isso, concluímos que o filme Trainspotting retrata como a toxicomania se encontra dentro das chamadas patologias do ato, ou seja, patologias em que a elaboração psíquica cede lugar à ação, abarcando sujeitos com uma importante fragilidade narcísica. E essa patologia está muito relacionada ao contexto social da sociedade contemporânea, que apresenta como característica o autocentramento e o individualismo. Neste sentido, a toxicomania caracteriza-se como um sintoma pós-moderno, que serve para evitar a dor e fugir da subjetividade.

\section{Referências}

1. Oliveira LA. Toxicomania e gozo. Psicol Rev. [Internet]. 2010 [Acesso 25 nov 2014];19(2):239-61. Disponível em: http://revistas.pucsp.br/index.php/psicorevista/article/ view/6725/4863.

2. Stacechen LF, Bento VES. Consumo excessivo na pós-modernidade: uma interpretação psicanalítica. Fractal Rev Psicol. [Internet]. 2008 [Acesso 25 nov 2014];20(2):421-36. Disponível em: http://www.scielo. br/scielo.php?pid=S198402922008000200009\&script=s ci_arttext

3. Kegler P. As patologias do narcisismo e a clínica psicanalítica: novas configurações subjetivas na contemporaneidade. [Monografia] Santa Maria (RS): Universidade Federal de Santa Maria; 2006.

4. Esper BEM, Neder M. O corpo contemporâneo. In: Anais da $1^{\text {a }}$ Convenção Brasil Latino, $4^{\circ}$ Congresso Brasileiro e $9^{\circ}$ Encontro Paranaense de Psicoterapias Corporais. Foz do Iguaçu; 2004. [Acesso 21 nov 2014]. Disponível em: http://www.centroreichiano.com.br/ artigos/Anais\%202004/Elisa\%20Maria\%20Barbosa\%20 Esper.pdf.

5. Birman J. Dor e sofrimento num mundo sem mediação. Rev Cult. 2003; 95:25-9.
6. Freud S. Carta 55 a Fliess de 11 de janeiro de 1897 , v. 1. In: Edição standard brasileira das obras psicológicas completas de Sigmund Freud. Rio de Janeiro: Imago; 1987. (trabalho original publicado em 1897).

7. Freud S. Carta 79 a Fliess de 22 de dezembro de 1897 , v.1. In: Edição standard brasileira das obras psicológicas completas de Sigmund Freud. Rio de Janeiro: Imago; 1987. (trabalho original publicado em 1897).

8. Freud S. O mal-estar na civilização, v. 21. Edição standard brasileira das obras psicológicas completas de Sigmund Freud. Rio de Janeiro: Imago; 1974. (trabalho original publicado em 1930).

9. Mendonça JRS. A droga como um recurso ao malestar na civilização. Psicol Rev. .[Internet]. 2011 [Acesso 25 nov 2014]; 17(2);240-60. Disponível em: http:// periodicos.pucminas.br/index.php/psicologiaemrevista/ article/viewFile/P.1678-9563.2011v17n2p240/3242.

10. Tomás MA. Intoxicação: um retorno à onipotênicia narcísica. Mosaicos: Estud Psicol.[Internet]. 2008 [Acesso 14 out 2014];2(1):35-43. Disponível em: http:// www.fafich.ufmg.br/mosaico/index.php/mosaico/article/ view/19/15.

11. Freud S. Além do princípio do prazer, v. 18. In: Edição standard brasileira das obras psicológicas completas de Sigmund Freud. Rio de Janeiro: Imago; 1977 (trabalho original publicado em 1920).

12. Lacan J. Os complexos familiares na formação do indivíduo, ensaio de análise de uma função em Psicologia. Rio de Janeiro: Zahar; 1985.

13. Lacan J. (1946/1998). Formulações sobre a causalidade psíquica. In: Escritos. Rio de Janeiro: Zahar; 1998. (trabalho original publicado em 1946).

14. D’Avila. O Complexo de Édipo na Teoria de Jacques Lacan. Dissertação (Mestrado em filosofia). São Carlos: Universidade Federal de São Carlos; 2001.

15. Gorski GG. Algumas considerações sobre o complexo de Édipo em Freud e Lacan. Mato Grosso: UFCG: Psicologiamedica. [Internet]. 1995. [Acesso 7 out 2014]. Disponível em: http://www.psiconica.com/psimed/ files/edipo_\%20em_freud_\%20lacan.pdf

16. Laznik-Penot MC. A construção do conceito de gozo em Lacan. Rev Percurso. [Internet]. 1992 [Acesso 21 nov 2014];5(8). Disponível em: http://revistapercurso.uol. com.br/pdfs/p08_texto01.pdf.

17. Valas P. As dimensões do gozo: do mito da pulsão à deriva do gozo. Rio de Janeiro: Jorge Zahar; 2001.

18. Lemos I. O gozo cínico do toxicômano. Mental. [Internet]. 2004 [Acesso 21 nov 2014];2(3):51-60. Disponível em: http://pepsic.bvsalud.org/scielo. php? pid=S1679-44272004000200005\&script $=$ sci_ arttext. 
19. Lacan J. (1966/2001). O lugar da psicanálise na medicina. Opção Lacaniana. 2001(32).

20. Santiago J. Lacan e a toxicomania: efeitos da ciência sobre o corpo. Ágora (Rio de Janeiro [Internet]. 2001 [Acesso 10 fev 2015];4(1):23-32. Disponível em: http:// www.scielo.br/scielo.php?script=sci_arttext\&pid=S1516$14982001000100002 \&$ Ing=en\&nrm=iso

21. Ribeiro CT. Que lugar para as drogas no sujeito? Que lugar para o sujeito nas drogas? Uma leitura psicanalítica do fenômeno do uso de drogas na contemporaneidade. Ágora. (Rio de Janeiro) [Internet]. 2009 [Acesso 13 nov 2014].;12(2):333-46. Disponível em: $\quad$ http://www.scielo.br/scielo.php?pid=S1516$14982009000200012 \&$ script=sci_arttext.

22. Bauman Z. Modernidade Líquida. Tradução: Plínio Dentzien. Rio de Janeiro: Zahar; 2003. 258 p. 